\title{
Ectopic pregnancy: reappraisal of risk factors and management strategies
}

\section{Swapna Mohan*, Mariam Thomas}

\author{
Department of Obstetrics \& Gynecology, Government Medical College, Ernakulam, Kerala, India
}

Received: 20 March 2015

Revised: 23 March 2015

Accepted: 09 May 2015

\section{*Correspondence: \\ Dr. Swapna Mohan, \\ E-mail: soppumohan@yahoo.co.in}

Copyright: (C) the author(s), publisher and licensee Medip Academy. This is an open-access article distributed under the terms of the Creative Commons Attribution Non-Commercial License, which permits unrestricted non-commercial use, distribution, and reproduction in any medium, provided the original work is properly cited.

\begin{abstract}
Background: The incidence of ectopic pregnancy is increasing. The objective of this study was to analyze the risk factors, clinical characteristics, and management strategies in patients with ectopic pregnancy at a tertiary care referral centre in South India.

Methods: Retrospective observational study was done for a period of seven years from April 2006 to March 2014 where in case files of 87 cases of ectopic pregnancies were analyzed for clinical profile, sonological data, management strategies and outcome.

Results: The incidence of ectopic pregnancy has increased from 8.3 in 2006 to $18.92 / 1000$ live births in 2014. Risk factors associated were prior tubal ligation $21(24.14 \%)$, history of pelvic inflammatory disease $11(12.64 \%)$, prior ectopic $5(5.75 \%)$, prior tubal surgery $4(4.60 \%)$, infertility $13(14.94 \%)$, prior pelvic surgery $22(25.29 \%)$ and current use of Copper T - $3(3.45 \%)$ cases. Common symptoms were lower abdominal pain in $80(91.95 \%)$ and amenorrhea in 76 (87.35) cases. 9 cases presented in shock. Gray scale ultrasound showed complex adnexal mass in 42 (48.28\%), tubal ring $19(21.84 \%)$ and live fetus in $11(12.64 \%) .72$ cases were managed surgically, 11 medically and 4 by expectant management. Tubal rupture occurred in 30(41.67\%). Among those managed surgically, laparotomy was done in $55(76.39 \%)$, laparoscopy in $17(23.61 \%)$ cases. Salpingectomy was done in $52(72.22 \%)$, salpingostomy 9 (12.5\%), salpingotomy $5(6.94 \%)$, segmental resection $3(4.17 \%)$, scar excision and repair 1 (1.39\%), abdominal hysterectomy $1(1.39 \%)$, and laparotomy for abdominal pregnancy in $1(1.39 \%)$ case. There was no maternal death.

Conclusions: The incidence of ectopic has been increasing. Prior sterilization particularly done along with caesarean is the most common risk factor in our region. Surgical management by laparotomy and salpingectomy continues to be the preferred mode of management of ectopic pregnancy in our institution since two third of patients are referred from periphery and present with considerable intraperitoneal hemorrhage.
\end{abstract}

Keywords: Ectopic pregnancy, Risk factors, Salpingectomy

\section{INTRODUCTION}

Ectopic pregnancy results when a fertilized oocyte implants outside the endometrial cavity. It is the leading cause of morbidity and mortality for women during first trimester of pregnancy. Ectopic pregnancy accounts for approximately $2 \%$ of all pregnancies. Recent reports indicate that the incidence of ectopic pregnancy has increased six fold during the last 30 years. ${ }^{1,2}$ This apparent increase in ectopic pregnancy owes to a true increase in disease due to increase in number of patients with risk factors, heightened awareness by clinicians and earlier diagnosis of cases that otherwise would have spontaneously resolved. $95 \%$ of ectopic pregnancies occur in fallopian tube and out of which $55 \%$ occur in ampulla, $20-25 \%$ isthmus, $17 \%$ fimbriae, $2-4 \%$ in interstitial segment, Other sites of ectopic pregnancy are 
0.5-1\% ovarian, $0.1 \%$ cervical and $0.03 \%$ abdominal pregnancy. ${ }^{3}$ Implantation within a caesarean scar is being increasingly reported. It is life threatening due to high risk of uterine rupture and bleeding. Damage to fallopian tube as in pelvic inflammatory disease, previous tubal surgery, tubal ligation and prior ectopic pregnancy are predisposing factors for ectopic pregnancy. Other risk factors include use of intrauterine device, infertility, multiple sexual partners, previous pelvic surgery and cigarette smoking. ${ }^{4,5}$

Diagnosis of ectopic pregnancy can be quite challenging. Clinical symptoms usually appear at 6-8 weeks. Classic triad of pain, bleeding and adnexal mass is seen in only $45 \%$. $^{6,7}$ Evaluation for suspected ectopic pregnancy should begin with a quantitative measurement of serum $\beta$-HCG levels and transvaginal ultrasound (TVUS). When TVUS fails to show an intra-uterine pregnancy at HCG level >1500-2000 mIU/ml, a diagnosis of ectopic pregnancy should be strongly suspected. Sonographic findings of ectopic pregnancy include presence of extra uterine gestational sac with yolksac or embryo (with or without heart beat), adnexal hyper echogenic ring, complex adnexal mass separate from ovary, free fluid and presence of pseudo gestational sac. Colour Doppler of tubal ring shows peritrophoblastic flow of low impedance and high diastolic flow.

Expectant treatment is suitable for asymptomatic women with hCG $<1000 \mathrm{mIU} / \mathrm{ml}$ with no evidence of blood in pouch of douglas. ${ }^{11}$ Medical management with methotrexate is suitable in women with minimal or no symptoms, hCG below $3000 \mathrm{mIU} / \mathrm{ml}$, adnexal mass of $<3.5 \mathrm{~cm}$ and absence of cardiac activity. ${ }^{11,12}$ Tubal rupture occurs in $7 \%$. Candidates for surgical treatment include women who are hemodynamically unstable, those with significant pain, those not suitable or have failed medical management and those desiring sterilization. ${ }^{11,12}$ A laparoscopic approach is preferable to an open approach in hemodynamically stable patients. ${ }^{11}$ Linear salpingostomy or salpingotomy is the procedure of choice in the presence of contralateral tubal disease and desire for future fertility. ${ }^{11,13}$ De-cherney and Boyers have found segmental resection preferable to salpingotomy in most cases of isthmic ectopics. ${ }^{14}$ Salpingectomy is a better choice for women with severely damaged tube, recurrent ectopic pregnancy in the same tube, uncontrolled bleeding after salpingostomy, heterotopic pregnancy and for those who have completed their family. ${ }^{11,15,16}$

Incidence of ectopic pregnancy has been increasing .Our hospital is tertiary care level referral hospital catering to poor socioeconomic population. In spite of improved diagnostic aids, we still receive a large number of patients referred from periphery with considerable intraperitoneal hemorrhage at presentation, who are candidates for surgical management by laparotomy. The present analysis looks into risk factors, clinical presentations, ultrasound findings, management strategies and outcome in our group of patients with ectopic pregnancies.

\section{METHODS}

This was a retrospective observational study done at department of Obstetrics and Gynecology at Government Medical College, a tertiary level teaching hospital in Ernakulam, Kerala, India. The study was approved by institutional ethical committee. Duration of study was from April 2006 to March 2014 for a period of seven years. Inclusion criteria: All cases of ectopic pregnancy, diagnosed based on clinical, biochemical and sonological criteria were included. Clinical features included amenorrhea, abdominal pain, and vaginal bleeding. Sonographic criteria include presence of extra uterine gestational sac with yolksac or embryo (with or without heart beat), adnexal hyper echogenic ring, complex adnexal mass, free fluid, and absence of intra uterine sac at HCG level of $>1500 \mathrm{mIU} / \mathrm{ml}$. Asymptomatic women with hCG $<1000 \mathrm{mIU} / \mathrm{ml}$ with no evidence of blood in pouch of Douglas were given expectant management. Women with no significant pain with hCG below 3000 $\mathrm{mIU} / \mathrm{ml}$, adnexal mass of $<3.5 \mathrm{~cm}$ and absence of cardiac activity were managed medically with methotrexate. Patients who were hemodynamically unstable, those with significant pain those not suitable or had failed medical management and those desiring sterilization were managed surgically. Salpingectomy was our choice in most cases. Salpingostomy or salpingotomy was done only in presence of unruptured ectopic and contralateral tubal disease. Laparoscopy was done only for hemodynamically stable patients and if surgeon on duty had experience in laparoscopy. Surgical notes of all patients were analyzed for indication of surgery, site of ectopic pregnancy, evidence of tubal rupture, amount of hemoperitoneum and details of surgical management. Presence of ectopic in surgical specimens was confirmed using standard haematoxylin eosin staining techniques. Post-operative outcome was noted in all patients. Descriptive statistics were determined.

\section{RESULTS}

A total of 87 cases of ectopic pregnancies were identified out of a total 5687 deliveries during the study period. The calculated incidence of ectopic pregnancy was 15.68/1000 live births. Age ranged from 18 to 41 years. Mean age was 28.47 years.

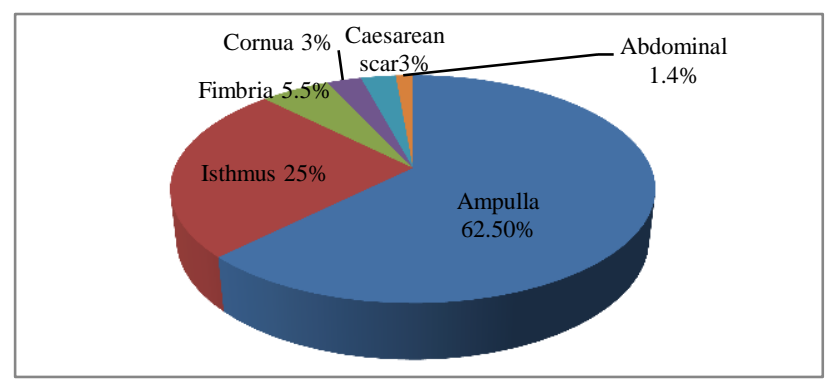

Figure 1: Shows sites of ectopic pregnancy in patients who underwent surgery. 
Table 1: Shows distribution of age.

\begin{tabular}{|llll|}
$\begin{array}{l}\text { Age } \\
\text { (years) }\end{array}$ & $\begin{array}{l}\text { No. of } \\
\text { cases }\end{array}$ & $\begin{array}{l}\text { Percentage } \\
(\%)\end{array}$ & $\begin{array}{l}\text { Mean age } \\
\text { (years) }\end{array}$ \\
\hline$\leq 20$ & 5 & $5.75 \%$ & 19.33 \\
\hline $21-25$ & 17 & $19.54 \%$ & 23.87 \\
\hline $26-30$ & 34 & $39.08 \%$ & 28.24 \\
\hline $31-35$ & 21 & $24.14 \%$ & 33.17 \\
\hline $36-40$ & 10 & $11.49 \%$ & 37.75 \\
\hline
\end{tabular}

Table 2: Shows distribution of risk factors in patients with ectopic pregnancy.

\begin{tabular}{|llll|}
\hline Risk factors & $\begin{array}{l}\text { No. of } \\
\text { cases }\end{array}$ & $\begin{array}{l}\text { Percentage } \\
(\%)\end{array}$ & $95 \%$ CI \\
\hline Prior tubal ligation & 21 & $24.14 \%$ & $(15.12,33.08)$ \\
\hline History of PID & 11 & $12.64 \%$ & $(5.66,19.62)$ \\
\hline $\begin{array}{l}\text { Prior ectopic } \\
\text { pregnancy }\end{array}$ & 5 & $5.75 \%$ & $(0.82,10.58)$ \\
\hline Prior tubal surgery & 4 & $4.60 \%$ & $(2,8.98)$ \\
\hline Current IUD use & 3 & $3.45 \%$ & $(0.38,7.28)$ \\
\hline History of infertility & 13 & $14.94 \%$ & $(7.45,22.43)$ \\
\hline Prior miscarriage & 19 & $21.84 \%$ & $(13.17,30.52)$ \\
\hline Prior pelvic surgery & 22 & $25.29 \%$ & $(16.15,34.41)$ \\
\hline Caesarean & 17 & $19.54 \%$ & $(11.21,27.87)$ \\
\hline Appendisectomy & 2 & $2.30 \%$ & $(0.85,5.43)$ \\
\hline $\begin{array}{l}\text { Ovarian cystectomy } \\
\text { / oopherectomy }\end{array}$ & 3 & $3.45 \%$ & $(0.38,7.28)$ \\
\hline
\end{tabular}

Age ranged from 18 to 41 years. Mean age was 28.47 years. Parity ranged from nulliparous to $3^{\text {rd }}$ parity. 24 $(25.59 \%)$ cases were nulliparous, $25(28.74 \%)$ with parity 1, $29(33.33 \%)$ cases with parity 2 and 9 cases $(10.34 \%)$ with parity 3. Mean parity was $1.5 .68(78.16 \%)$ women had known risk factors at presentation.

Most common risk factor was prior tubal ligation, in $21(24.14 \%)$ cases. $61.9 \%$ of those with prior tubal ligation had sterilization done along with caesarean and $38.09 \%$ had sterilization in post-partum period by minilaparotomy. There was no case of tubal ectopic following laparoscopic interval sterilization. Duration from sterilization procedure to ectopic pregnancy varied from 11 months to 14 years. Pelvic inflammatory disease was seen in $11(12.64 \%)$ and prior ectopic in $5(5.75 \%)$ cases. Some patients had multiple risk factors.

Table 3: Shows clinical features at presentation $(n=87)$.

\begin{tabular}{|lll|}
\hline Clinical features & $\begin{array}{l}\text { No. of } \\
\text { cases }\end{array}$ & $\begin{array}{l}\text { Percentage } \\
(\%)\end{array}$ \\
\hline Amenorrhoea & 76 & $87.35 \%$ \\
\hline Lower abdominal pain & 80 & $91.95 \%$ \\
\hline Vaginal bleeding & 42 & $48.27 \%$ \\
\hline Vomiting & 22 & $25.29 \%$ \\
\hline Syncope & 17 & $19.54 \%$ \\
\hline Urinary complaints & 11 & $12.64 \%$ \\
\hline Shoulder pain & 4 & $4.6 \%$ \\
\hline Chest pain* & 1 & $1.15 \%$ \\
\hline Back ache* & 2 & $2.30 \%$ \\
\hline Pain loin to groin & 1 & $1.15 \%$ \\
\hline Shock & 9 & $9.20 \%$ \\
\hline Fever & 2 & $2.30 \%$ \\
\hline Guarding/rigidity & 16 & $18.40 \%$ \\
\hline Adnexal tenderness & 80 & $91.95 \%$ \\
\hline Cervical motion tenderness & 46 & $52.87 \%$ \\
\hline Adnexal mass & 20 & $22.99 \%$ \\
\hline
\end{tabular}

Most common symptom in our study was lower abdominal pain, in $80(91.95 \%)$ cases. Amenorrhea was present in $76(87.35 \%)$ cases, whereas vaginal bleeding in $42(40.27 \%)$ cases. Mean gestational age was 6.3 weeks Classic triad of pain, bleeding and adnexal mass was seen in only $35(40.23 \%)$ cases. $9(9.20 \%)$ cases presented in shock. Peritoneal signs were present in 16 (18.40\%). 2 cases presented with back ache alone, 1 case with chest pain alone and 1 case with loin pain alone.

Table 4: Shows relation of amenorrhea to different sites of tubal ectopic pregnancies in patients who were surgically managed $(n=72)$.

\begin{tabular}{|c|c|c|c|c|c|c|c|}
\hline \multirow{2}{*}{ Amenorhea } & \multicolumn{4}{|c|}{ Tubal pregnancies } & \multirow{2}{*}{$\begin{array}{l}\text { Abdominal } \\
\text { pregnancy }\end{array}$} & \multirow{2}{*}{$\begin{array}{l}\text { Caesarean } \\
\text { scarpregnancy }\end{array}$} & \multirow{2}{*}{$\begin{array}{l}\text { Total } \\
\text { cases (\%) }\end{array}$} \\
\hline & Ampulla & Isthmus & Fimbria & Cornua & & & \\
\hline Nil & 5 & 4 & 0 & 0 & 0 & 0 & $9(12.5 \%)$ \\
\hline 29-42 days & 22 & 11 & 2 & 1 & 0 & 0 & $36(50 \%)$ \\
\hline 43-56 days & 15 & 2 & 2 & 0 & 0 & 2 & $21(29 \%)$ \\
\hline $57-70$ days & 3 & 1 & 0 & 0 & 0 & 0 & $4(5.56 \%)$ \\
\hline 71-84 days & 0 & 0 & 0 & 0 & 0 & 0 & $0(0 \%)$ \\
\hline$>84$ days & 0 & 0 & 0 & 1 & 1 & 0 & $2(2.78 \%)$ \\
\hline Total cases (\%) & $45(62.5)$ & $18(25)$ & $4(5.5)$ & $2(2.8)$ & $1(1.39)$ & $2(2.78)$ & 72 \\
\hline
\end{tabular}


$50 \%$ of patients had amenorrhea of $28-48$ days in this group.

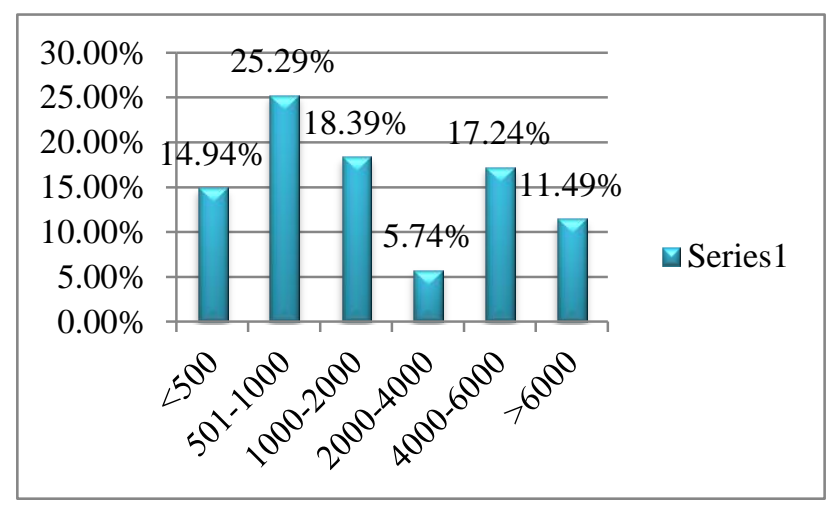

Figure 2: Shows hCG levels at presentation.

HCG levels in mIU

HCG levels ranged from 46 to $8220 \mathrm{mIU} / \mathrm{ml}$. Mean HCG was $1017 \mathrm{mIU} / \mathrm{ml} .37(42.53 \%)$ patients had $\beta$-hCG $<1000 \mathrm{mIU} / \mathrm{ml}$.

Table 5: Shows ultrasound features of ectopic pregnancy.

\begin{tabular}{|lll|}
\hline Ultrasound features & $\begin{array}{l}\text { No. of } \\
\text { cases }\end{array}$ & $\begin{array}{l}\text { Percentage } \\
(\%)\end{array}$ \\
\hline Complex adnexal mass & 42 & $48.28 \%$ \\
\hline Hyperechogenic tubal ring & 19 & $21.84 \%$ \\
\hline Gestational sac, live fetal pole & 11 & $12.64 \%$ \\
\hline Significant free fluid & 33 & $37.93 \%$ \\
\hline Increased vascularity on Doppler & 27 & $31.03 \%$ \\
\hline
\end{tabular}

Complex adnexal mass was the most common finding, seen in $42(48.28 \%)$ cases. Power Doppler showed increased vascularity in $27(31.03 \%)$ cases on sonogram. $6(6.90 \%)$ cases did not have any positive findings other than free fluid. Endometrial thickness were in the range of $3.5 \mathrm{~mm}$ to $27 \mathrm{~mm}$. The mean endometrial thickness was $13.07 \mathrm{~mm}$.

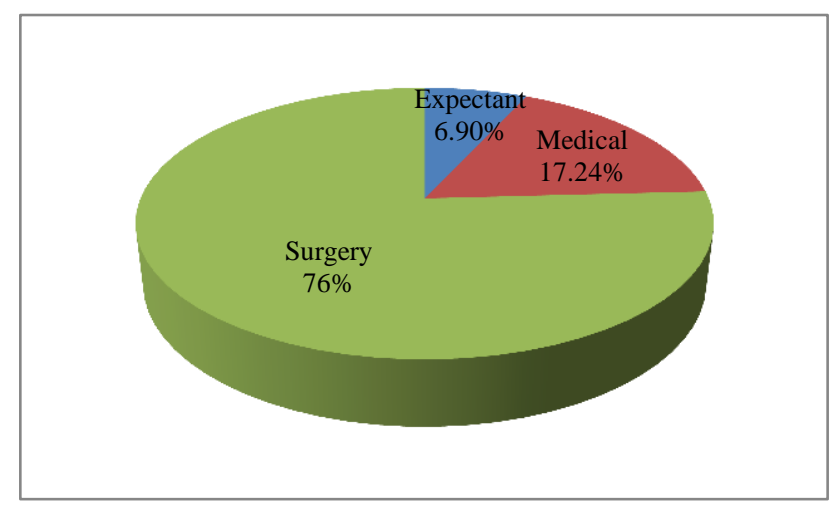

Figure 3: Shows initial management strategies in cases of ectopic.
6 cases of ectopic pregnancy underwent expectant management initially, but surgery was necessary in 2 cases on follow up due to increased pain and suspected rupture. 15 cases underwent medical management with methotrexate, 11 cases $(73.33 \%)$ were successfully treated with methotrexate, 8 cases with one dose, 3 cases with 2 doses. Surgery was eventually needed in 4 cases due to significant pain suggestive of rupture. 72 of all cases were managed surgically. Following are the details of 72 patients with ectopic pregnancy who underwent surgery

Table 6: Shows indications for surgery $(n=72)$.

\begin{tabular}{|lll|}
\hline Indications for surgery* & $\begin{array}{l}\text { No. of } \\
\text { cases }\end{array}$ & $\begin{array}{l}\text { Percentage } \\
(\%)\end{array}$ \\
\hline Hemodynamically unstable patient & 18 & $25 \%$ \\
\hline Sterilization failure & 21 & $29.17 \%$ \\
\hline Unsuitable for methotrexate & 8 & $11.11 \%$ \\
\hline Failed medical management & 4 & $5.56 \%$ \\
\hline Failed conservative management & 2 & $2.78 \%$ \\
\hline Desires sterilization & 12 & $16.67 \%$ \\
\hline Chronic ectopic & 3 & $4.17 \%$ \\
\hline Caesarean scar pregnancy & 2 & $2.78 \%$ \\
\hline Abdominal pregnancy & 1 & $1.39 \%$ \\
\hline
\end{tabular}

*Some cases had $>1$ indication

Common indications for surgery were ectopic pregnancy in a patient who had undergone tubal ligation 21 (29.17\%) cases and hemodynamic instability 18 (25\%) cases due to profuse intra peritoneal hemorrhage. Some patients had $>1$ indication. Laparotomy was initial management of choice in $55(76.38 \%)$ patients. The indications for laparotomy were hemodynamic instability, pelvic adhesions, chronic ectopic, abdominal pregnancy, caesarean scar pregnancy, and cornual pregnancy. Out of tubal ectopic pregnancies $38(55.07 \%)$ were in right tube and $31(44.93 \%)$ in left tube.

Table 7: Shows intraoperative findings in tubal ectopic pregnancies.

\begin{tabular}{|lllll|}
\hline Findings & $\begin{array}{l}\text { Sites of tubal ectopic } \\
\text { Ampulla } \\
(\mathbf{n , ~ \% )}\end{array}$ & $\begin{array}{l}\text { Isthmus } \\
(\mathbf{n}, \%)\end{array}$ & $\begin{array}{l}\text { Cornua } \\
(\mathbf{n ,}, \%)\end{array}$ & $\begin{array}{l}\text { Fimbriae } \\
(\mathbf{n ,} \%)\end{array}$ \\
\hline $\begin{array}{l}\text { Tubal } \\
\text { rupture }\end{array}$ & $\begin{array}{l}14 \\
(19.44 \%)\end{array}$ & $\begin{array}{l}14 \\
(19.44 \%)\end{array}$ & 0 & $\begin{array}{l}2 \\
(2.78 \%)\end{array}$ \\
\hline $\begin{array}{l}\text { Tubal } \\
\text { abortion }\end{array}$ & $\begin{array}{l}23 \\
(31.94 \%)\end{array}$ & 0 & 0 & 2 \\
\hline $\begin{array}{l}\text { Unruptured } \\
\text { ectopic }\end{array}$ & 5 & 4 & 2 & 0 \\
\hline $\begin{array}{l}\text { Chronic } \\
\text { ectopic }\end{array}$ & $\begin{array}{l}(6.94 \%) \\
(4.17 \%)\end{array}$ & $(5.56 \%)$ & $(2.78 \%)$ & 0 \\
\hline
\end{tabular}

Tubal rupture with hemoperitoneum occurred in 30 $(41.67 \%)$ of the 72 cases, partial tubal abortion with hemoperitoneum in $25(34-72 \%)$, unruptured ectopic in 11 $(15.28 \%)$ and chronic ectopic in $3(4.17 \%)$ cases. 


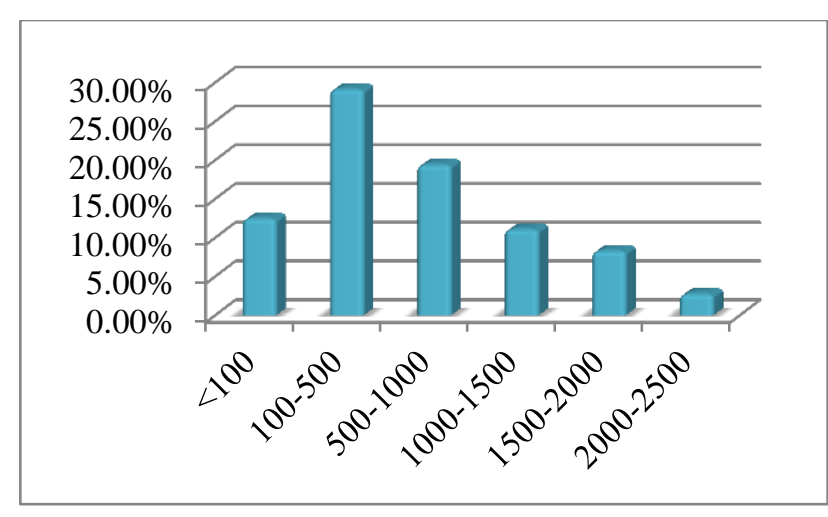

Figure 4: Shows haemoperitoneum in the 60 patients with intraperitoneal hemorrhage.

Hemoperitoneum in $\mathrm{ml}$

$16(22.22 \%)$ patients had intraperitoneal hemorrhage of more than 1 litre.

Table 8: Shows surgical procedures done for ectopic pregnancy $(n=72)$.

\begin{tabular}{|c|c|c|c|c|}
\hline Surgery & Laparotomy & Laparoscopy & $\begin{array}{l}\text { Total } \\
\text { No. of } \\
\text { cases }\end{array}$ & $\%$ \\
\hline Salpingectomy & 44 & 8 & 52 & $72.22 \%$ \\
\hline Salpingostomy & 0 & 9 & 9 & $12.5 \%$ \\
\hline Salpingotomy & 5 & 0 & 5 & $6.94 \%$ \\
\hline $\begin{array}{l}\text { Segmental } \\
\text { resection }\end{array}$ & 3 & 0 & 3 & $4.17 \%$ \\
\hline $\begin{array}{l}\text { Scar excision } \\
\& \text { repair }\end{array}$ & 1 & 0 & 1 & $1.39 \%$ \\
\hline $\begin{array}{l}\text { Laparotomy } \\
\text { for abdominal } \\
\text { pregnancy }\end{array}$ & 1 & 0 & 1 & $1.39 \%$ \\
\hline $\begin{array}{l}\text { Abdominal } \\
\text { hysterectomy }\end{array}$ & 1 & 0 & 1 & $1.39 \%$ \\
\hline
\end{tabular}

Salpingectomy was the most common procedure done in $52(72.22 \%)$ cases. Tubal conservation was possible in 17 $(23.61 \%)$ cases. None of them required salpingectomy later.

Table 9: Shows indications for salpingectomy in $\mathbf{5 2}$ patients.

\begin{tabular}{|lll|} 
Indications* & $\begin{array}{l}\text { No. of } \\
\text { cases }\end{array}$ & $\begin{array}{l}\text { Percentage } \\
(\%)\end{array}$ \\
\hline Prior tubal ligation & 21 & $40.39 \%$ \\
\hline Chronic ectopic & 3 & $5.77 \%$ \\
\hline Ruptured ectopic/unsalvageable tube & 11 & $21.15 \%$ \\
\hline Recurrent ectopic & 3 & $5.77 \%$ \\
\hline Patient request/ declines fertility & 12 & $23.08 \%$ \\
\hline
\end{tabular}

*Some cases had $>1$ indication

Prior tubal ligation $21(40.39 \%)$ and ruptured ectopic or unsalvageable tube $11(21.15 \%)$ and patient request 12
(23.08) were common indications. Post-operative complications occurred in $9(12.5 \%)$ patients. They were fever in 6 cases, wound infection in 1 case and paralytic ileus in 1 case. All patients with complications had a prolonged hospital stay for $\geq 8$ days. There was no maternal death in our series.

\section{DISCUSSION}

Over the past twenty five years, there is a remarkable change in the incidence, risk factors, diagnostic aids and management of ectopic pregnancy. The study shows an increase in incidence over years from 2006 to 2014, from $8.3 / 1000$ live births to $18.92 / 1000$ live births. Various studies from India and abroad show an increasing incidence of ectopic pregnancy. ${ }^{17-19}$ Mean age in our study was 28.5 years. More than half of the women were of lower parity (parity one or less). This is comparable to other studies. ${ }^{18-20}$

Ankum et al. in study of risk factors for ectopic pregnancy in 1996 has suggested that previous ectopic pregnancy (OR 6.6), \& history of tubal ligation (OR 9.3) as high risk factors and history of PID (OR 2.5) and history of infertility (OR 2.5) as moderate risk factors for ectopic pregnancy. Three fourth of our patients had known risk factors. ${ }^{4}$ Various studies have shown PID as the commonest risk factor, present in upto $40 \% .^{18-20}$ Though in our study, PID was a risk factor in only $13 \%$. Contrary to all the studies done before, most common risk factor in our study was prior tubal ligation, present in one third of cases, majority $(62 \%)$ of which are tubal ligations done along with caesarean section. This may be due to high acceptance of female sterilization as family planning method, by our population, which is supported by Indian government as a method to control population explosion. In our country majority of women opt for concurrent or postpartum sterilization, This is done commonly by modified Pomeroy's method. Tubal ligation done along with delivery is associated with increased chance of tubal recanalization and failure, with a higher incidence of tubal pregnancies following tubal ligation. The type of procedures our patients had undergone were not clear from their records. Higher incidence of sterilization failure in our population is significant and needs further appraisal by large studies. Following standard practices of sterilization procedure, encouraging interval sterilization and alternate methods of family planning will certainly decrease number of ectopic pregnancies due to sterilization failure.

Diagnosis of ectopic pregnancy can be quite challenging because presentation can vary significantly. $10 \%$ of cases had no history of amenorrhea or abdominal pain. Vaginal bleeding was the only presenting complaint in three patients. Three patients were referred from surgery department with a diagnosis of renal calculi, urinary infection and appendicitis respectively. Few patients presented with back ache or chest pain or loin pain alone. Clinician need to have high index of suspicion with regard to unusual presentations of ectopic. Barnhart et al., 
in a study of symptomatic women, had found hCG levels between 501 to 2000 and 2000-4000 associated with OR 1.73 and 1.38 respectively for ectopic pregnancy. ${ }^{5} 60 \%$ of patients in our study had hCG levels between $\leq 2000$ at presentation. This supports the fact that ectopic pregnancies are associated with lower levels of HCG. Even at very low levels of $<200$, one cannot exclude ectopic pregnancy in symptomatic patients.

In a 10 year population based study of 1800 cases of ectopic pregnancy, Bouyer et al., suggested sites of ectopic pregnancy as ampullary (70\%), isthmic (12\%), fimbrial $(11 \%)$, interstitial $(2.4 \%)$, ovarian $(3.2 \%)$ and abdominal $(1.3 \%){ }^{3}$ The results of our study are comparable. However there were no cervical or ovarian pregnancies in our series. Our study also had 2 cases of caesarean scar pregnancy $(2.78 \%)$. The true incidence of pregnancy in scar has not been determined. However due to increasing number of caesarean sections being performed the incidence is on the increase. Mean gestational age at presentation after excluding abdominal pregnancy was 6.2 weeks. Mean gestational age was 7 weeks and 7.4 weeks in studies done by Caminiti et al. and 1 gwegbe et al respectively. ${ }^{17,20}$ Interestingly in this study more than $60 \%$ of cases presented at $<7$ weeks gestation. This may be due to early diagnosis and more number of ectopic becoming symptomatic and undergoing rupture at early gestation. In our study, tubal rupture occurred in $42 \%$ of patients. Rate of tubal rupture varies greatly between various studies from $16 \%, 36 \%$, $83.1 \% .^{13,17,21}$

Most of our patients belong to low socio economic status, thin built with pre-existing anemia, living in remote areas and being referred from, nearby government hospitals with established diagnosis of ectopic pregnancy. Around half of the patients were hemodynamically unstable at presentation. Hence surgery was the main stay of treatment at initial presentation in three fourth of patients. In our series laparotomy was the preferred mode of surgery in the presence of hemodynamic instability and previous surgery. A quarter of the patients were managed by laparoscopy. In a similar study from northern India laparotomy was done in $73 \%$ and laparoscopy in $30 \% .^{19}$ On the contrary, in a study by Payal et al, all 43 cases of ectopic pregnancy including cornual pregnancy and those with hemodynamic instability were managed by laparoscopy. ${ }^{22}$ However laparotomy was our preferred method for cornual, caesarean scar and abdominal pregnancy. In a national survey done in UK by Taheri et al., $57 \%$ of ectopic pregnancies were managed by laparoscopy and only $5 \%$ by laparotomy where most of the centres had facilities for TVUS and laparoscopy over 24 hours. $^{23}$

The decision to perform conservative versus radical tubal surgery is on the basis of patients' history, desire for future fertility and surgical findings. Three fourth of all cases were managed with salpingectomy as this was the choice for all cases of tubal rupture and sterilization failure. Salpingectomy rates of other studies are Caminiti et al. $83 \%$, Majhi et al $81.9 \% .^{17,24}$ This is comparable with our study, whereas study by Payal et al. on laparoscopic management, had a salpingectomy rate of $53.5 \% .^{22}$ Salpingostomy was our preferred choice in unruptured ampullary ectopic pregnancies and contralateral tubal disease. One case of caesarean scar pregnancy was treated by scar excision \& repair due to uterine rupture. One case of caesarean scar pregnancy, referred from outside with severe vaginal bleeding following attempted evacuation for an ultrasound diagnosis of incomplete miscarriage, required abdominal hysterectomy as a life-saving procedure. Both cases of cornual pregnancies were treated by salpingotomy. Laparotomy was needed for a case of abdominal pregnancy diagnosed at 16 weeks in a women following treatment for infertility.

Since most of our patients were referred with established signs of ruptured tubal pregnancy, and hemodynamic compromise, they needed emergency laparotomy and salpingectomy as life saving measures. High index of suspicion and awareness among clinicians, early use of routine transvaginal ultrasound to locate pregnancy and measuring hCG levels in any women in reproductive age who present with abdominal pain and vaginal bleeding, irrespective of amenorrhea is vital in diagnosing ectopic pregnancy at an early stage. This allows medical management and conservative tubal surgery in most cases with better reproductive potential. With easy accessibility to Ultrasound \& advanced operative laparoscopy on a 24 hour basis in the government sector in Southern India, more cases of ectopic pregnancies can be diagnosed early and managed in a minimally invasive manner which is beneficial for patients particularly in poor socioeconomic class.

Strength of this study is that all the data were collected by the principle investigator. Clinical data and surgical notes were complete in all cases. Surgical specimens of all cases were confirmed by histopathological study. Limitations of this study are that secondary data was collected retrospectively. Random sampling could not be adopted due to lack of proper follow up. Number of cases which were medically managed were less. Due to lack of accessibility to sophisticated laparoscopy instruments some cases, especially those with prior surgeries and hemoperitoneum, could not be managed using minimally invasive route. Future prospective studies comparing different surgical techniques and fertility outcome and studies to analyze cases of sterilization failure are beneficial.

\section{CONCLUSION}

Incidence of ectopic pregnancy has increased over past few years. Prior sterilization particularly done along with caesarean seems to be the most common risk factor associated with increasing incidence of ectopic pregnancy in our region. Surgical management by laparotomy and salpingectomy continues to be the preferred mode of 
management of ectopic pregnancy in our institution since two third of patients are referred and present with considerable intraperitoneal hemorrhage.

\section{ACKNOWLEDGEMENTS}

The author wishes to acknowledge help rendered by Dr. Leela in collecting case records from medical records department. The author also wishes to record deep sense of gratitude to the Principal, Government Medical College, Ernakulam, for providing necessary facilities to carry out the research.

Funding: No funding sources

Conflict of interest: None declared

Ethical approval: The study was approved by the institutional ethics committee

\section{REFERENCES}

1. Centre for Disease Control and Prevention. Ectopic pregnancy mortality - Florida, 2009-2010. Morb Mortal Wkly Rep. 2012;61(6):106-9.

2. Chang J, Elam Evans JD, Berg CJ. Pregnancy related mortality surveillance - United States 1991-1999. MMWR Surveill Summ. 2003;52:1-9.

3. Bouyer J, Coste J, Fernandez H. Sites of ectopic pregnancy, a 10 year population based study of 1800 cases. Human Reprod. 2002;17:3224-30.

4. Ankum WM, Mol BWJ, Vander Veen R. Risk factors for ectopic pregnancy: a meta-analysis. Fertil Steril. 1996;65(6):1093-9.

5. Kurt TBanhart, Claris R, Amy C. Risk factors for ectopic pregnancy in women with symptomatic first trimester pregnancies. Fertil Steril. 1996;86:36-42.

6. Pisarka M, Carson SA, Buster SE. Ectopic pregnancy. Lancet. 1998;351:1115.

7. Dart RG, Kaplan B, Varaklis K. Predictive value of history and physical examination in patients with suspected ectopic pregnancy. Ann Emerg Med. 1999;33:283-90.

8. Jurkovic D, Marvelos D. Ultrasound diagnosis of ectopic pregnancy. Ultrasound Obstet Gynecol. 2007;30:1-7.

9. Schwartz RO, Di Pietro DL. $\beta-H C G$ as a diagnostic aid for suspected ectopic pregnancy. Obstet Gynecol. 1980;56:197.

10. Fernandez H, Rain horn JD, Papiernik E. Spontaneous resolution of ectopic pregnancy. Obstet Gynecol. 1988;71:171.
11. The management of tubal pregnancy. RCOG guideline No: 21, 2004. Available at: https://www.rcog.org.uk/en/guidelines-researchservices/guidelines/gtg21/.

12. Nice Clinical Guideline (CG154). Ectopic pregnancy and miscarriage: Diagnosis and initial management in early pregnancy of ectopic pregnancy and miscarriage, December 2012. Available at: https://www.nice.org.uk/guidance/cg154.

13. Langer R, Bukovsky, Herman A. Conservative surgery for tubal pregnancy. Fertil Steril. 1982;38:427.

14. De Cherney AH, Boyers SP. Isthmic ectopic pregnancy- segmental resection as treatment of choice. Fertil Steril. 1985;44:307.

15. Dubuisson JB, Morice P, Chapron C. Salpingectomy. The laparoscopic surgical choice for ectopic pregnancy. Human Reprod. 1996;11:1199.

16. Tulandi T, Saleh A. Surgical management of ectopic pregnancy. Clin Obstet Gynecol. 1999;42(1):31-8.

17. Deanna D, Caminiti MD, Kathleen L. Smith. An institutional review of the management of Ectopic pregnancy. J Gynecol Surg. 2006;22(2):47-56.

18. Rose Jophy, Annamm Thomas. Ectopic pregnancy 5 years' experience. J Obstet Gynecol India. 2002;52(4):55-8.

19. Promila Jindal, Sunitha Goyal. Clinical profile and outcome of ectopic pregnancies in northern India. Indian J Obstet Gynecol. 2013;(3):23-7.

20. Igwegbe A, Elenje G, Okpala B. An appraisal of the management of ectopic pregnancy in a Nigerian tertiary hospital. Ann Med Health Sci Res. 2013;3(2):166-70.

21. Lawani OL, Anozie OB, Ezeonu PO. Ectopic pregnancy: a life threatening gynecological emergency. Int J Women's Health. 2013;19(5):51521.

22. Chaudhary Payal, Manchanda Patil. Retrospective study on laparoscopic management of ectopic pregnancy. J Obstet Gynecol India. 2012;63(3):1736.

23. Taheri M, Bharathan R, Subramanian A, Kelly T. A UK national survey of trends in ectopic pregnancy management. J Obstet Gynecol. 2014;34(6):508-11.

24. Majhi AK, Roy N, Karmakar KS, Banargee PK. Ectopic pregnancy-an analysis of 180 cases. J Indian Med Assoc. 2007;105(6):308-12.

DOI: $10.18203 / 2320-1770.1 j r \operatorname{cog} 20150078$

Cite this article as: Mohan S, Thomas M. Ectopic pregnancy: reappraisal of risk factors and management strategies. Int J Reprod Contracept Obstet Gynecol 2015;4:709-15. 